\title{
Analysis of the goldfish Carassius auratus olfactory epithelium transcriptome reveals the presence of numerous non-olfactory GPCR and putative receptors for progestin pheromones Nikolay N Kolmakov ${ }^{1}$, Michael Kube ${ }^{2}$, Richard Reinhardt ${ }^{2}$ and Adelino VM Canario*1
}

Address: ${ }^{1}$ Centro de Ciências do Mar, Universidade do Algarve, Campus de Gambelas, 8005-139 Faro, Portugal and ${ }^{2}$ MPI Molecular Genetics, Ihnestrasse 63-73, D-14195 Berlin-Dahlem, Germany

Email: Nikolay N Kolmakov - nkolmakov@ualg.pt; Michael Kube - kube@molgen.mpg.de; Richard Reinhardt - rr@molgen.mpg.de; Adelino VM Canario* - acanario@ualg.pt

* Corresponding author

Published: 20 September 2008

BMC Genomics 2008, 9:429 doi:10.1 186/1471-2164-9-429
Received: 18 March 2008

Accepted: 20 September 2008

This article is available from: http://www.biomedcentral.com/I47I-2I64/9/429

(c) 2008 Kolmakov et al; licensee BioMed Central Ltd.

This is an Open Access article distributed under the terms of the Creative Commons Attribution License (http://creativecommons.org/licenses/by/2.0), which permits unrestricted use, distribution, and reproduction in any medium, provided the original work is properly cited.

\begin{abstract}
Background: The goldfish (Carassius auratus) uses steroids and prostaglandins as pheromone cues at different stages of the reproductive cycle to facilitate spawning synchronization. Steroid progestin pheromone binding has been detected in goldfish olfactory membranes but the receptors responsible for this specific binding remain unknown. In order to shed some light on the olfactory epithelium transcriptome and search for possible receptor candidates a large set of EST from this tissue were analysed and compared to and combined with a similar zebrafish (Danio rerio) resource.

Results: We generated 4,797 high quality sequences from a normalized cDNA library of the goldfish olfactory epithelium, which were clustered in 3,879 unique sequences, grouped in 668 contigs and 3,2II singletons. BLASTX searches produced 3,243 significant (E-value $<\mathrm{e}^{-10}$ ) hits and Gene Ontology (GO) analysis annotated a further I,223 of these genes (37.7\%). Comparative analysis with zebrafish olfactory epithelium ESTs revealed I,088 identical unigenes. The transcriptome size of both species was estimated at about 16,400 unigenes, based on the proportion of genes identified involved in Glucose Metabolic Process. Of I24 G-protein coupled receptors identified in the olfactory epithelium of both species, 56 were olfactory receptors. Beta and gamma membrane progestin receptors were also isolated by subcloning of RT-PCR products from both species and an olfactory epithelium specific splice form identified.
\end{abstract}

Conclusion: The high similarity between the goldfish and zebrafish olfactory systems allowed the creation of a 'cyprinid' olfactory epithelium library estimated to represent circa $70 \%$ of the transcriptome. These results are an important resource for the identification of components of signalling pathways involved in olfaction as well as putative targets for pharmacological and histochemical studies. The possible function of the receptors identified in the olfactory system is described. Moreover, the role of olfactory epithelium specific isoforms of classical membrane progestin receptor genes as candidates for preovulatory pheromone sensing is discussed. 


\section{Background}

Chemical senses play an important role in aquatic organisms, affecting many aspects of their biology. In teleost fish, social behaviour, reproduction, homing, schooling, search for food and predator avoidance are all regulated by the sense of smell [1-3]. In addition, because of its origin and structure, the olfactory epithelium is the first tissue to be affected by any toxic agent that fish encounter in the natural environment $[4,5]$ and heavy metal accumulation in the fish brain directly affects signal transduction in the central nervous system [6]. However, despite the existence of many physiological and behavioral studies about olfaction in fish, the molecular mechanisms of signal transduction and regulation of olfaction is not fully understood.

It has been proposed that olfactory receptor proteins responsible for odorant recognition belong to the large superfamily of G-protein coupled receptors (GPCR)[7]. Genome-wide analysis of several fish species has provided some data about the number and variability of GPCRs in fish. Indeed, genomic studies of zebrafish (Danio rerio), tiger puffer fish (Takifugu rubripes) and medaka (Orizias latipes) have led to the identification of three main receptor classes possibly involved in olfaction and pheromone communication. These are the principal olfactory receptors (Class A - rhodopsin-like), vomeronasal-type 2 (VT2; Class C - Ca sensing and metabotropic glutamate receptors) as well as a recently described vomeronasal-type 1 homolog class (closely related to Class A) which contains few members $[8,9]$. The zebrafish genome contains approximately 140 hypothetical Class A receptors, while in puffer fishes there are 44 and approximately 50 Class $C$ receptors $[8,9]$. Relatively few of the receptors have been isolated as cDNA and some are expressed in tissues other than the olfactory epithelia, raising questions about their exclusive role in olfaction.

Despite the importance of the goldfish (Carassius auratus) for behavioural studies and its well characterised pheromonal system [10], only 22 receptors have been cloned so far, 4 from class A and 18 from class C [11-13]. Moreover, for only a single olfactory receptor, OR5.24, has ligand preference been characterised and shown to bind positively charged, amino acids [12]. However, a wide group of chemicals are known to induce a physiological response in the goldfish. Such chemicals include, amino acids and polyamines [14], which are the main signal for recognition of food and danger; bile acids which are involved in social behaviour between conspecifics or related species [15]; steroids, mainly the progestins

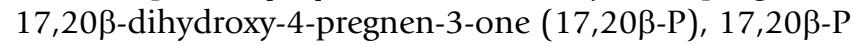
sulphate and androstenedione, which synchronize gonadal maturation among sexes [16,17], and prostaglandin $F_{2 \alpha}\left(P F_{2 \alpha}\right)$, which elicits spawning behaviour [18]. It has been shown that steroid- and prostaglandin responses are at least partly mediated by the cyclic AMP signalling pathway [19] and that olfactory epithelium cells have steroid-binding activity [20].

The objective of the present study was to obtain insight into molecular mechanisms of olfactory and in particular pheromone signaling by analysing expressed sequence tags (ESTs) of the goldfish olfactory epithelium. Identification of candidate genes potentially involved in the regulation and structural organization of olfactory signaling pathways in fish should contribute to extend knowledge of receptors and auxiliary proteins underpinning olfaction. To this end an EST collection produced from a normalized cDNA library of the olfactory epithelium from sexually mature goldfish was analysed. Comparison of olfactory epithelium ESTs from goldfish and zebrafish, both cyprinids, allowed an estimation of transcriptome size in the goldfish olfactory epithelium to be made. The presence of splice variants of membrane progestin receptors (PAQR) are reported for the first time in olfactory epithelium together with genes involved in their regulation. A number of new olfactory and other G-protein coupled receptors have been identified as well as a group of Class A subfamily receptors, closely related to Xenopus amino acid olfactory receptors.

\section{Results and Discussion \\ Descriptive statistics of Expressed Sequence Tags}

A total of 6,144 EST were produced from a normalized goldfish olfactory epithelium cDNA library. After subtraction of poor quality sequences, the average length per EST of the remaining sequences $(4,797)$ was 608 base pairs. The sequences were assembled into 668 contigs and 3,211 singletons (Table 1) [see Additional file 1]. Because further assembling was not possible, the sequences obtained were considered unigenes, each unigene representing the product of a separate gene. Unigenes corresponded to about four-fifths of the total sequences obtained (Table 1). Most of the genes identified were isolated for the first time in this species, highlighting the paucity of gene expression studies in the species. Normalization was highly efficient as demonstrated by a low skewness (4.56) and kurtosis (37.6). Contigs were composed of multiple

Table I: Summary of goldfish EST sequences analysis

\begin{tabular}{lc}
\hline & \\
\hline Total ESTs sequenced & 6144 \\
Sequences passed quality control & 4797 \\
Average length per good quality EST (bp) & 608 \\
Number of contigs & 668 \\
Number of singletons & 3211 \\
Total of unigenes & 3879 \\
Unigenes with database hits & $3243(83.6 \%)$ \\
Unigenes with a known function & $1464(37.7 \%)$
\end{tabular}


ESTs with a maximal depth of 11 . Only 9 contigs had a depth of more than 5 and the upper 25 percentile contained only $41.4 \%$ of all ESTs. By comparison, zebrafish ESTs pooled from two non-normalized olfactory epithelium libraries comprised 6,696 unigenes from 34,699 counts. Pooling of the two zebrafish olfactory epithelium libraries did not significantly change redundancy - skewness of the pooled zebrafish EST libraries was 13.76 versus 13.91 for the average of the two separate libraries, and kurtosis was 233.3 versus 245.4. Maximal contig depth in the pooled libraries was 512 EST counts and the upper 25 th percentile contained $80.1 \%$ of total EST counts. The percentage of goldfish unigene sequences which had a statistically significant similarity to genes deposited in GenBank was $83.6 \%$, compared to $92.6 \%$ for the pooled zebrafish olfactory epithelium unigenes.

\section{Comparison between Goldfish and Zebrafish olfactory epithelium ESTs}

The similarity of the goldfish and zebrafish olfactory epithelium EST collections was examined using side-by-side comparison of the total list of identified genes. Unidentified goldfish unigenes were further compared to the pooled zebrafish EST olfactory library using BLASTn with an E-value $<\mathrm{e}^{-40}$. From the preceding analysis, a total of 1,088 common unigenes were obtained, of which 44 lacked annotation to known gene products. The goldfish unigenes were evenly represented throughout the frequency distribution range of unigenes in the zebrafish non-normalized library, suggesting representation bias was minimal or absent in the goldfish library (Figure 1). To further substantiate the observed lack of representation bias in the normalized goldfish olfactory epithelium library, one thousand clones were randomly picked and sequenced from a non-normalized, goldfish olfactory epithelium library (not described) and yielded 253 unigenes. Comparative analysis of the 253 unigenes with the goldfish normalized library and zebrafish pooled library revealed 66 and 131 matches, respectively and 104 unigenes which were absent from both libraries. The ratio of goldfish/zebrafish matches in the latter analysis was $50.4 \%$, similar to the results obtained for the normalized goldfish library, further supporting the notion of a lack of amplification bias during the normalization process.

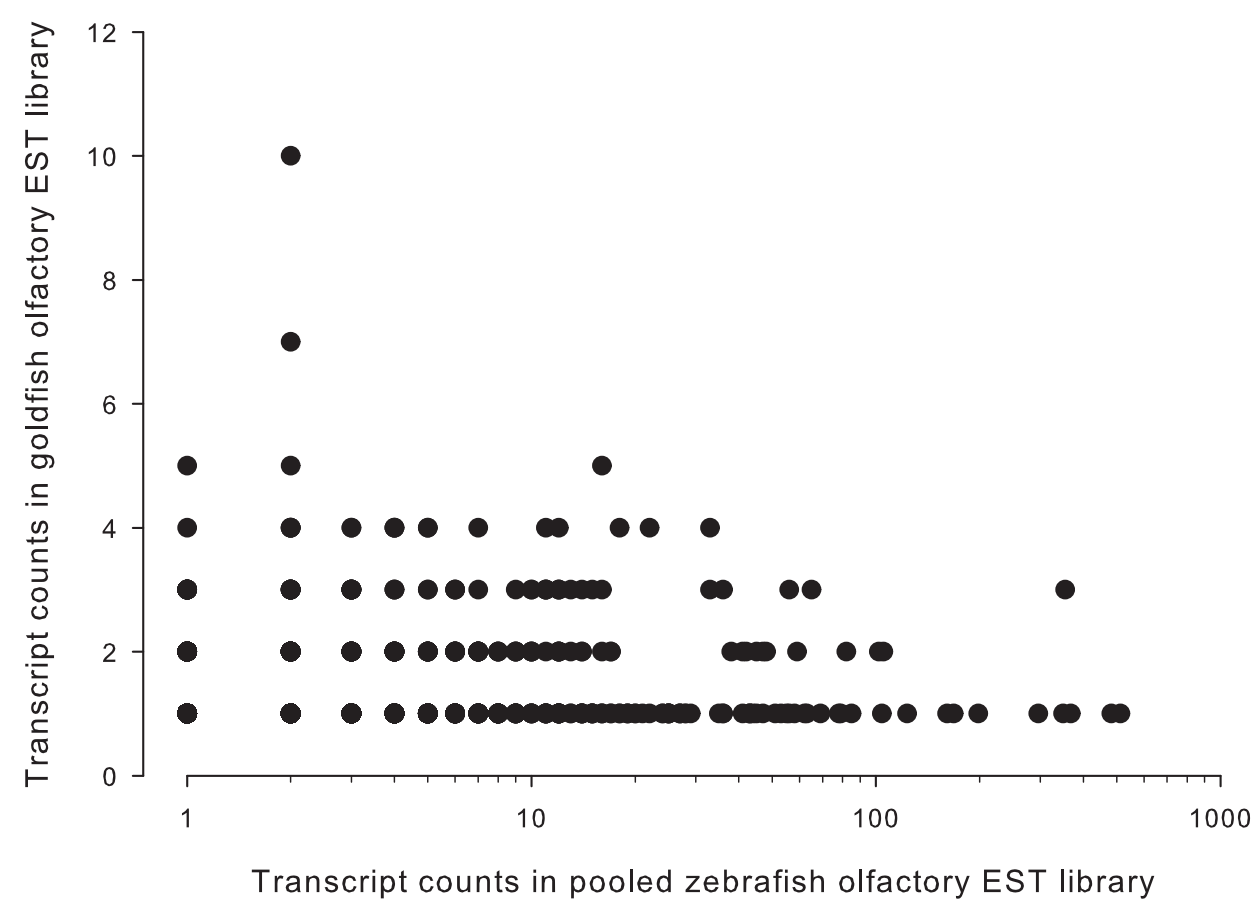

Figure I

Frequency of common transcripts between goldfish and zebrafish olfactory EST libraries. Semi-logarithmic plot of counts of each transcript present in both the goldfish normalized and zebrafish non-normalized EST library. The almost uniform relationship $(R=0.009)$ is a strong indication of absence of amplification bias during normalization. 


\section{Transcriptome estimation}

In order to obtain an estimate of the goldfish olfactory epithelium transcriptome size, a list of 75 genes associated with Glucose Metabolic Process in animals was extracted from the Gene Ontology (Table 2). Of these genes, $15(20 \%)$ were present in the normalized goldfish olfactory epithelium EST collection and 28 (37.3\%) were found in the pooled zebrafish olfactory epithelium library. Extrapolation of the proportion of Glucose Metabolic Process genes in these libraries to the total number of unigenes for each library gave an estimate of the olfactory epithelium transcriptome size of, respectively, 16215 and 16612 unigenes for goldfish and zebrafish. The ratio of Glucose Metabolic Process genes present in the goldfish and zebrafish EST libraries (53.6\%) was similar to the ratio of the number of unigenes present in the two libraries $(52.3 \%)$. This is in agreement with the hypothesis that the transcriptome of this tissue in the two species is of a similar size.
The close phylogenetic relationship between goldfish and zebrafish and the almost identical size of estimated transcriptome of their respective olfactory epithelia led us to combine the ESTs from the two species into a "cyprinid" olfactory epithelium transcriptome. In order to do this identical unigenes were treated as the same, while closely related genes (same gene subfamily, subunits of the same protein complex, etc.) were listed separately. Any information about levels of expression was removed, thus the list contains information only about presence of genes in the olfactory epithelium. As a result, 9,596 unique sequence identifiers were assembled, which comprised $58.5 \%$ of the estimated cyprinid olfactory epithelium transcriptome. This percentage is what would be predicted based on the unigenes obtained from the non normalized goldfish olfactory epithelium, in which clones absent from goldfish and zebrafish libraries comprised $41.1 \%$ (compared to expected random picking of $41.5 \%$ ). As a result we estimate that the "cyprinid" olfactory epithelium transcriptome is approximately 16,400 unigenes.

Table 2: Unigenes from the Glucose Metabolism category (GO:006006) in goldfish and zebrafish olfactory epithelium collections

\begin{tabular}{|c|c|c|}
\hline Genes only in goldfish OE transcriptome & Genes in $O E$ unigene libraries of both species & Genes only in zebrafish $O E$ transcriptome \\
\hline cAMP responsive element modulator & Activating transcription factor 4 & 3-hydroxyisobutyrate dehydrogenase \\
\hline Hexokinase I & Aldolase 2, B isoform & $\begin{array}{l}\text { 6-phosphofructo-2-kinase/fructose-2,6- } \\
\text { biphosphatase } 3\end{array}$ \\
\hline $\begin{array}{l}\text { Nuclear receptor subfamily } 3 \text {, group C, } \\
\text { member I }\end{array}$ & $\begin{array}{l}\text { Glycerol-3-phosphate dehydrogenase I } \\
\text { (soluble) }\end{array}$ & 6-phosphogluconolactonase \\
\hline Phosphofructokinase, platelet & Leptin & $\begin{array}{l}\text { Adiponectin, } \mathrm{CIQ} \text { and collagen domain } \\
\text { containing }\end{array}$ \\
\hline Ribose 5-phosphate isomerase A (predicted) & Phosphoglucomutase 3 & $\begin{array}{l}\text { Aldhehyde dehydrogenase family } 5 \text {, subfamily } \\
\text { Al }\end{array}$ \\
\hline $\begin{array}{l}\text { Solute carrier family 2, (facilitated glucose } \\
\text { transporter), member } 8\end{array}$ & Ribulose-5-phosphate-3-epimerase (predicted) & $\begin{array}{l}\text { Calcium channel, voltage-dependent, P/Q type, } \\
\text { alpha IA }\end{array}$ \\
\hline \multirow[t]{14}{*}{ Transketolase } & Transaldolase I & cAMP-regulated phosphoprotein 19 \\
\hline & Triosephosphate isomerase I & Carbonic anhydrase $5 \mathrm{a}$, mitochondrial \\
\hline & & Carnitine palmitoyltransferase la, liver \\
\hline & & Enolase I, alpha \\
\hline & & Fatty acid binding protein 5 , epidermal \\
\hline & & Glucose phosphate isomerase I \\
\hline & & Glucose-6-phosphate dehydrogenase X-linked \\
\hline & & $\begin{array}{l}\text { Glyceraldehyde-3-phosphate dehydrogenase, } \\
\text { spermatogenic }\end{array}$ \\
\hline & & Insulin-like growth factor binding protein I \\
\hline & & Myelocytomatosis oncogene \\
\hline & & $\begin{array}{l}\text { Protein kinase, AMP-activated, alpha I catalytic } \\
\text { subunit }\end{array}$ \\
\hline & & Pyruvate dehydrogenase (lipoamide) beta \\
\hline & & Pyruvate kinase, muscle \\
\hline & & Tumor necrosis factor \\
\hline Total number of Glucose Metabolism genes & 75 & $100 \%$ \\
\hline Positive matches to goldfish OE library & 15 & $20 \%$ \\
\hline Positive matches to zebrafish OE library & 29 & $37.3 \%$ \\
\hline Unmatched genes & 40 & $53.3 \%$ \\
\hline
\end{tabular}

Positive matches include counts of genes present in both libraries. For this reason the sum of present and absent genes exceeds the total number of genes used in analysis. 
Taken together these data support the use of the "cyprinid" unigene set in further analysis of olfactory epithelium gene expression.

\section{General description of genes in the transcriptome}

Since normalization of the goldfish olfactory epithelium library was highly efficient, it is not possible to use it to determine the level of expression of the most abundant mRNA species using ESTs counts. For this purpose the list of unigenes from the pooled zebrafish library was used. The unigenes with a redundancy level higher than $0.5 \%$ are listed in Table 3.

The 20 most expressed genes in the olfactory epithelium of adult zebrafish could be divided into four groups: 1) immune response, 2) cell machinery and cytoskeleton, 3) tissue specific function and 4) unidentified. Immune response genes were represented by 4 genes from both MHCI (invariant chain-like protein 1 and 2, HLA-B associated transcript 5) and MHCII (beta-2-microglobulin) [21]. Cell machinery genes included those encoding 3 ribosomal proteins, mitochondrial carrier slc25a4, betaactin, tubulin, tubulin-related tctp (tpt1) and iron-sequestering ferritin [22-24]. Also in this group elongation factor 1 -alpha, related to protein synthesis in general, was most abundant. Among genes generally highly expressed in epithelial or neuronal tissue and expected to have a high level of expression in olfactory epithelium, were apolipoprotein E, tyrosinase-related protein 1 and G-protein beta subunit homologue RACK1. Apolipoprotein E plays an important role in lipid transport and lipoprotein metabolism, both processes involved in the formation of the olfactory epithelium mucosa [25]. The gene for tyrosinase-related protein 1 is involved in pigmentation and melanin synthesis [26]. GNB2L1(RACK1) is a key element of cell migration and adhesion through integrins and IGF and is highly expressed in epithelial cells and fibroblasts [27]. Twelve of the most abundant zebrafish transcripts were also identified in goldfish olfactory epithelium, including the four of immune response genes, apolipoprotein E and G-protein beta subunit homologue. A recent analysis of a small set of channel catfish (Ictalurus puntactus) olfactory epithelium ESTs reported by Li et al. [28] also described the presence of immune system genes, including invariant chain-like proteins, cytokines and lymphocyte markers, and some other non-neuronal elements also identified in goldfish and zebrafish by our analysis. The expression of these genes in independently produced cDNA libraries of the olfactory system of the three species suggests it is not due to possible contamination with other tissues and corresponds to the expectation of a well developed specific immune barrier, necessary to protect the unique neuronal tract, which directly links the brain with environment.

The unigenes of the goldfish olfactory epithelium library with identity to known gene products were assigned to Gene Ontology (GO) categories using data from Gene

Table 3: Genes highly represented in the zebrafish olfactory library

\begin{tabular}{|c|c|c|c|}
\hline \multicolumn{2}{|c|}{ EST count } & \multirow[t]{2}{*}{ Gene name } & \multirow[t]{2}{*}{ Gene description } \\
\hline Percentage & Copies & & \\
\hline 1.48 & 512 & EEFIa & Elongation factor I-alpha.* \\
\hline 1.39 & 482 & ApoE & Apolipoprotein Eb* \\
\hline 1.38 & 480 & $\mathrm{n} / \mathrm{a}$ & Unknown protein \\
\hline 1.25 & 433 & $|c| p \mid$ & Invariant chain-like protein I* \\
\hline 1.20 & 416 & $A c t b$ & Beta-actin 2 \\
\hline 1.14 & 395 & $\mathrm{n} / \mathrm{a}$ & Zgc: 112103 \\
\hline 1.06 & 368 & Slc25a4 & Similar to solute carrier family 25 (mitochondrial carrier; adenine nucleotide translocator), member $4^{*}$ \\
\hline 1.06 & 368 & Rplpo & Ribosomal protein, large, $\mathrm{PO} *$ \\
\hline 1.02 & 354 & Fthl & Ferritin, heavy polypeptide I* \\
\hline 1.00 & 349 & $B 2 m$ & Beta-2-microglobulin* \\
\hline 0.98 & 341 & Tyrpl & Tyrosinase-related protein I \\
\hline 0.89 & 309 & Gnb2II & Guanine nucleotide binding protein (G protein), beta polypeptide 2-like I(RACKI)* \\
\hline 0.85 & 296 & Bat5 & Similar to HLA-B associated transcript 5 , rat orthologue* \\
\hline 0.82 & 286 & $\mathrm{n} / \mathrm{a}$ & Unknown protein \\
\hline 0.74 & 257 & Iclp2 & Invariant chain-like protein $2^{*}$ \\
\hline 0.72 & 250 & Tpt I & Similar to translationally-controlled tumor protein \\
\hline 0.67 & 232 & Rpl4 & Ribosomal protein L4 \\
\hline 0.60 & 208 & Tuba6 & Similar to tubulin alpha 6 \\
\hline 0.57 & 198 & Rpl8 & Ribosomal protein L8* \\
\hline 0.53 & 185 & $\mathrm{n} / \mathrm{a}$ & Wu:fc48a I 2* \\
\hline
\end{tabular}

Twenty most represented ESTs in zebrafish olfactory epithelium. Stars indicate matches to goldfish olfactory epithelium. 
Ontology and GeneCards databases. A total of 1,464 unigenes was successfully assigned to 10,335 GO categories. Within the Molecular Function category, most of the identified proteins were involved in binding $(45.7 \%)$, catalytic activity $(28.7 \%)$, transporter $(5.6 \%)$, and signal transducer activity $(6.9 \%)$. In terms of physiological processes, the most represented unigenes correspond to cellular process $(29.8 \%)$, metabolism (20.9\%), and biological regulation (11.7\%) (Figure 2). When comparing with gene ontology categories of channel catfish gill epithelium [28] some specificities become evident. For example, the representation of both transcription regulatory mechanisms and DNA binding proteins in gill is proportionally twice that of the olfactory epithelium possibly because of a higher diversity of cell types (e.g., cartilage, bone, different types of epithelial cells) in gills. In contrast, at the translational level the olfactory epithelium has a higher proportion of regulatory elements and protein binding representatives. Also, within the binding category in olfactory epithelium there were some elements, absent from gill, possibly related to the tissues sensory function, such as over-represented genes involved in nucleotide (mainly cAMP) and ion $\left(\mathrm{Ca}^{2+}, \mathrm{Na}^{+}\right.$and $\left.\mathrm{Cl}^{-}\right)$binding. Furthermore, comparison of Biological Processes revealed a higher proportion of genes involved in growth, development and apoptotic mechanisms in the olfactory epithelium possibly reflecting intensive recirculation of the neurons.

\section{GPCR receptor repertoire in the olfactory epithelium Class I GPCRs - Rhodopsin family}

Several dozen G-protein coupled receptors were identified in the fish olfactory epithelium tissue as one or more EST copies, the majority belonged to Class I or the Rhodopsin family. This class could be further subdivided into three major subgroups: 1) immune system related receptors, 2) receptors to purines, pirimidines, and hormones, as well as neuromediator-related receptors and 3 ) olfactory receptors and orphan GPCRs.

\section{GPCRs related to the immune system}

This subgroup (Table 4) includes GPCRs containing the C-C motif chemokine receptors 5 and $6\left(\mathrm{ccr}^{*}\right), \mathrm{C}-\mathrm{X}-\mathrm{C}$ motif receptors $3.2,4,5$ and $7\left(\mathrm{cxcr}^{*}\right)$, leucotiene $\mathrm{B} 4$ receptor 2 (ltb4r2), GPRs 34b, 63 and 132. The EpsteinBarr-virus-induced G-protein coupled receptor 2 (ebi2) is also part of this subgroup. CCR 5 is expressed in lymphoid organs such as thymus and spleen, as well as in peripheral blood leukocytes, including macrophages and T cells, and stimulates leukocyte chemotactic activity through generation of inositol phosphates in the presence of macrophage inflammatory protein 1 [29]. CCR6 expression is restricted to functionally mature memory $\mathrm{B}$ cells, capable of responding to antigen challenge [30]. Splice variant 2 of CXCR3 has been shown to play a key role in transduction of the angiostatic effect of cytokines in microvascular endothelial cells [31]. Chemokine receptor 4 (cxcr4) affects cell-cycle proteins in hippocampal or cerebellar granule neurons and through cytokine binding represses the activity of E2F-dependent apoptotic genes to maintain neurons in a highly differentiated and quiescent state [32]. The ligand CXCL12 is a main axon guidance agent in the zebrafish olfactory system [33]. CXCR7 is a co-receptor for CXCR4 in B-, T-cells and monocytes [34]. CXCR5 is a cytokine receptor involved in B-cell activation and chemoattraction [35]. GPR132 is predominantly expressed in lymphocytes and macrophages where it serves as a mitosis delay mechanism under control of lysophosphatidylcholine and endogenous lysophosphatidic acid DNA damage signals [36]. GPR34 is the receptor for lysophosphatidylserine in mast cells. It is reported to be expressed in brain and adipose tissue and is involved in wound healing [37]. Endothelial differentiation G-protein coupled receptor $5(E d g 5)$ is a receptor for sphingosine 1-phosphate, which is responsible for neurite retraction and also keratinocyte growth arrest and differentiation during wound healing [38]. G protein-coupled receptor 63 (GPR63) is homologous to Xenopus PSP24 $\beta$ [39] which is expressed mainly in neuronal cells, such as olfactory mitral cells, cortical neurons, hippocampus pyramidal cells, and Purkinje cells in the cerebellum. Preliminary studies proposed sphingosine-1-phosphate as the ligand and G-protein $\alpha \mathrm{q}(\mathrm{G} \alpha \mathrm{q})$ as an effector for this receptor [40]. Leukotriene $\mathrm{B}(4)$ receptor 2 is expressed in mononuclear lymphocytes and provokes chemotaxis in a pertussis toxin-sensitive manner, relating its action to activation of the Gai pathway [41]. GPR81 is an orphan receptor, similar to neurotensin receptor, which is exclusively expressed in T-cells [42]. EBV-induced G-protein coupled receptor 2(ebi2) is most closely related to the thrombin receptor. It is expressed in B-lymphocyte cell lines, lymphoid tissues and is also expressed at lower levels in a promyelocytic (glial precursor) cell line [43].

Expression of such a comprehensive immune repertoire is puzzling as immune cells are generally of low abundance in the olfactory epithelium and have been reported in the basal layer of epithelium, as shown in Labeo rohita [44]. One possible explanation could be that cytokines, in addition to their role as mediators of the immune response are also involved in nervous system development and neuronal differentiation [45]. Moreover, as significant proliferation of neurons takes place in the olfactory system elements of the immune system may be part of a selective internal mechanisms of sensory cell population regulation via apoptotic mechanisms [46]. An insight into the possible role for different types of immune cells, as well as astroglia, in this process may be derived from multiple sclerosis models, where de-myelination and neuronal degradation mechanisms have been shown [47]. 

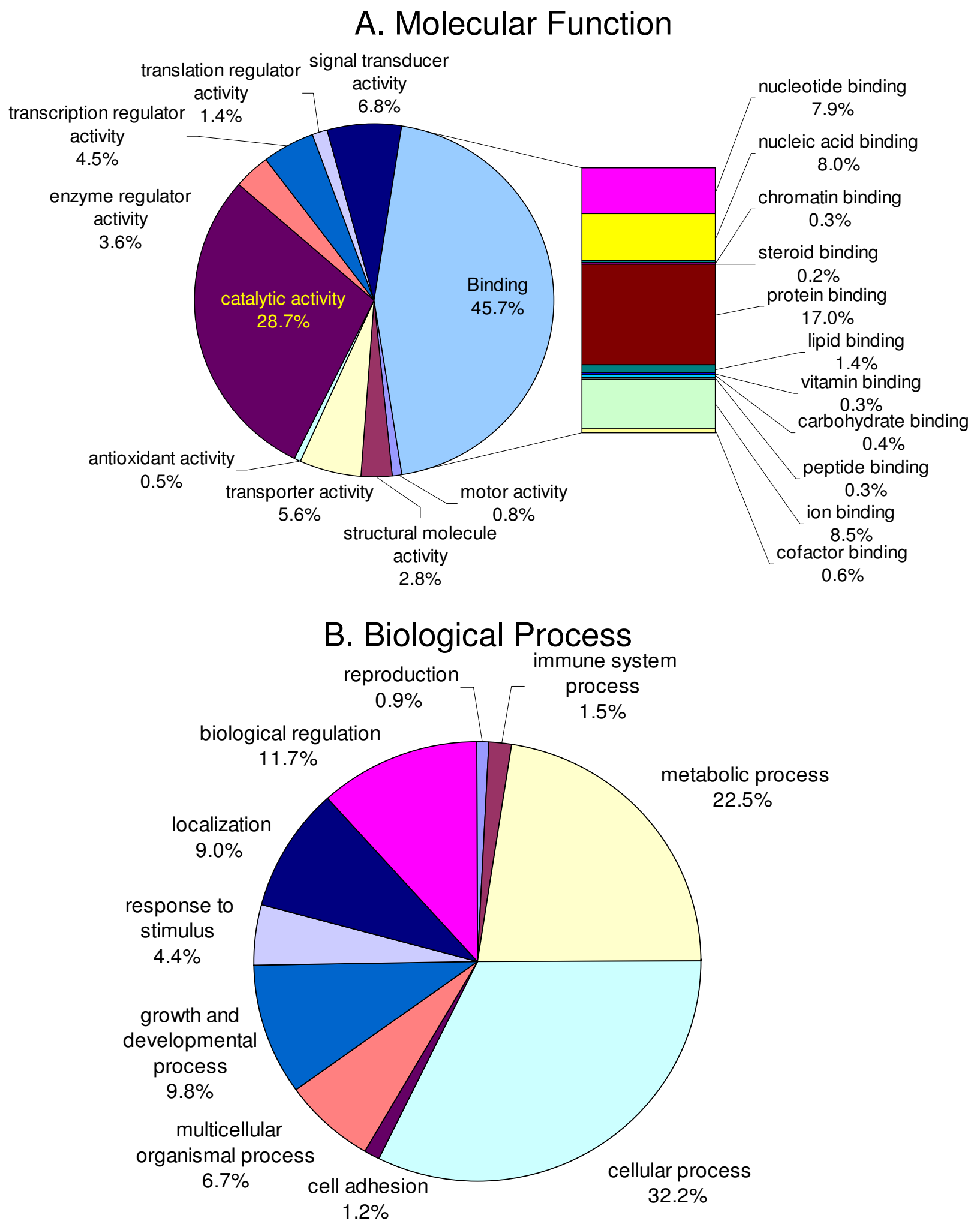

Figure 2

Classification of EST according to Gene Ontology. Distribution of goldfish olfactory epithelium unigenes classified using GeneOntology categories of (A) Molecular Function and (B) Biological Process. 
Table 4: Known function of immune system GPCRs

\begin{tabular}{|c|c|}
\hline \multicolumn{2}{|r|}{ Cytokine receptors } \\
\hline Chemokine (C-C motif) receptor 5 & Stimulates leukocyte chemotactic activity \\
\hline Chemokine (C-C motif) receptor 6 & Associated with mature memory B cells \\
\hline Chemokine (C-X-C motif) receptor 3 splice 2 & Transduction of angiostatic effect of cytokines in microvascular endothelial cells \\
\hline Chemokine (C-X-C motif) receptor 4 & Neuronal survival; maintaining of highly differentiated neurons; axon guidance \\
\hline Chemokine (C-X-C motif) receptor 7 & Co-receptor for CXCR4 in B-, T-cells and monocytes \\
\hline Chemokine (C-X-C motif) receptor 5 & B-cell activation and chemoattraction \\
\hline \multicolumn{2}{|r|}{ Non-cytokine receptors } \\
\hline EBV-induced G-protein coupled receptor 2 & B-lymphocyte and promyelocytic (glial precursor) cell line regulation \\
\hline GPR34 & Lysophosphatidylserine receptor in mast cells; wound healing \\
\hline GPR8I & Exclusively expressed in T-cells; neurotensin-related \\
\hline GPRI32 & Mitosis delay under control of lysophosphatidylcholine in lymphocytes and macrophages \\
\hline Leukotriene $B(4)$ receptor 2 & Chemotaxis of mononuclear lymphocytes \\
\hline Prostaglandin E2 receptor EP4 (PTGER4) & Stimulates immune response in B-cells and monocytes \\
\hline P2YIO (putative nucleotide receptor) & Monocyte development \\
\hline
\end{tabular}

GPCRs related to immune system expressed in fish olfactory epithelium.

GPCRs for purines, pirimidines, hormones and neuromediators This subgroup includes P2Y5, 6, 7, 10; 5-HT (serotonin) receptor $\mathrm{F} 1$, beta-3b-adrenergic receptor, prostaglandin E2 receptor EP4 (ptger4), gastrin-releasing peptide (bombesin) receptor and histamine receptor $\mathrm{H} 2$.

A ligand for purinergic receptor 5 ( $p 2 r y 5)$ still has to be identified [48]. Pyrimidinergic receptor P2Y6 ( $p 2 r y 6)$ is expressed in human nasal epithelial cells and activates the IP3 signaling pathway in the presence of UDP, and regulates mucin and fluid secretion [49]. P2RY7 is a leukotriene $\mathrm{B}(4)$ receptor, regulated by GRK6 and is responsible for extracellular ATP-dependent regulation of L-type $\mathrm{Ca}^{2+}$ channels. P2Y10 has so far not been identified as a nucleotide activated receptor, but has been shown to be involved in monocyte development [48]. While the exact cell type, expressing nucleotide receptors in fish is still unknown, there is the possibility that they can be involved in olfactory response modulation in response to noxious odorants, as shown in mice [50]. They could also be immediate olfactory receptors, since the fish olfactory epithelium is able to sense several nucleotides [51].

5-HT1F is a sumatriptan-sensitive serotonin receptor shown to be preferentially expressed in trigeminal ganglia and brain blood vessels where it plays role in regulation of migraine development [52]. It is also a potent inhibitor of olfactory responses in goldfish (Kolmakov et al, personal observation). The recently discovered trace amineassociated receptors (TAAR) [53] are also expressed in the cyprinid olfactory epithelium, with only one homologue each of TAAR9 and TAAR3 identified in goldfish. At least 24 TAAR ESTs have been identified in zebrafish olfactory epithelium [54], although 57 intact genes have been reported to be present in the genome [55]. Based on the 17 TAAR transcripts present in our "cyprinid" olfactory library we suggest approximately 40-45 TAAR genes are expressed in the olfactory epithelium of cyprinids. Although a role for TAAR receptors in mammalian olfaction of pheromonal volatile amines has been reported, there is still no direct evidence for a role in fish olfaction [54]. However, the expression of TAAR homologues in sea lamprey (Petromyzon marinus) olfactory epithelium is supportive of the notion that TAARs are an ancient group of olfactory receptors [56]. Perhaps their close phylogenetic relationship to biogenic amine receptors may indicate that in fish they serve, together with 5-HT1F, as receptors for catecholamines, potent odorants in goldfish [57]. Another possibility could be a role as part of a regulatory signal transduction mechanism with ligands like lysophosphatidic acid and sphingosine, similar to a group of the phylogenetically closely related endothelial differentiation G-protein coupled receptors (EDGs), also expressed in the olfactory epithelium.

The prostaglandin $\mathrm{E}_{2}$ receptor EP4 (ptger4) is an effector of $\mathrm{PGE}_{2}$ inhibition of bone-resorbing activity in functionally mature osteoclasts [58]. It also stimulates the immune response in B-cells and monocytes [59]. An EST was isolated sharing similarity only to the second translated exon of ptger4, while the N-terminus did not give any match to the zebrafish genome or any other database. Taking into account that in most prostaglandin receptors the first translated exon encodes 6 of the 7 transmembrane helices, including the putative ligand-binding pocket [60], and that they share a high level of sequence similarity in the second translated exon, this new cDNA could be a new receptor, probably still from the tromboxane/prostaglandin family. It will be of interest in the future to determine if it is a candidate receptor for $\mathrm{PGF}_{2 \alpha}$ the postovulatory pheromone in goldfish.

The beta-3b-adrenergic receptor, together with the beta-2adrenoreceptor are able to form heterodimers with other 
GPCRs of class A, altering their ligand specificity, signaling pathway and internalization $[61,62]$. In mice, the beta-2-adrenoreceptor co-expresses with olfactory receptors and is necessary for their successful translocation to the cell surface [63]. Finally, the bombesin receptor is involved in synaptic plasticity regulation in brain, as well as regulation of a broad spectra of behaviors including feeding and social interaction [64] while the histamine receptor is shown to be important for activation of astrocytes in neonatal rat brain [65].

\section{Olfactory receptors and orphan GPCRs}

This subgroup includes GPR108 and its homologue TMEM87B both members of the LUSTR family of proteins containing a carboxy-terminal seven transmembrane domain. They are expressed in fungiform papillae in humans and are suggested to be taste receptors [66]. Orphan GPR137 shares identity with a prostate-specific odorant-like GPCR-encoding gene (PSGR) and was detected mainly in hippocampus [67]. Orphan GPR161 is expressed in rat brain and olfactory epithelium and at a lower level in liver [68]. GPR173 is member 3 of the so called "Super Conserved Receptor Expressed in Brain" SREB family, which is highly conserved amongst vertebrates. SREB3 member is predominantly expressed in the brain, mainly cerebellum, and ovaries, but not in testis, and remains an orphan receptor [69].

Twelve putative ORs were identified in the goldfish olfactory epithelium EST collection. Based upon the classification of Alioto and Ngai [8], the receptors were assigned to several families: family A members 112-1 and 113-1; family C member 102-1; family D members 107-1, 110-1, 111-10; family E members 125-1, 127-1, 128-5 and three of family F member 115-1 homologues. The average similarity to zebrafish OR was higher than $80 \%$ for all the identified goldfish cDNA. Based on the predicted transcriptome size, it seems probable that 45-50 rhodopsinlike olfactory receptors are expressed in the goldfish olfactory epithelium. OR107-1 is a zebrafish homologue of the previously cloned goldfish receptor GFA2 [11]. Other goldfish olfactory receptors also present in the EST have previously been isolated in families C (GFA12, GFA25, CaOR45) and E (GFA28) [11]. Family C is closely related to long-chain non polar aminoacid olfactory receptors of Xenopus tropicalis, XB107, 238, 239 and 242 [70]. Two of the members of this family share the same correlated mutational analysis patterns, a strong reason to suspect similarity of ligands [71] making family members good candidate olfactory receptors for methionine, valine, leucine and cysteine.

Additional olfactory receptors were identified by RT-PCR, including receptors from families $\mathrm{C}, \mathrm{D}, \mathrm{E}$ and $\mathrm{F}$ and a homologue of the single member of family $\mathrm{B}$ (101-1). The total number of confirmed OR genes expressed in the goldfish olfactory epithelium when the results of RT-PCR are taken together with the EST analysis is 41 , which closely matches the predicted number of ORs. Surprisingly, neither the goldfish EST annotation, nor RT-PCR were able to identify members of the proposed families G and $\mathrm{H}$, while in the zebrafish olfactory epithelium only a single receptor from family $G$ and 6 receptors from family $\mathrm{H}$ have been identified. Also and searches through pufferfish, stickleback and medaka genomes failed to find any family $\mathrm{G}$ member which until appears to be restricted only to the zebrafish genome [8]. This may reflect selective adaptation of the zebrafish olfactory system to environmental conditions related to a species specific duplication even and is supported by the fact that the largest cluster of TAAR genes [72] is located less than 2 megabases away on the same chromosome and those genes are also specific for zebrafish.

\section{Class II GPCRs - Secretin family}

A number of transcripts belonging to the second class of GPCRs (Secretin/VIP family) were identified and include, calcitonin receptor-like receptor ( $\mathrm{calcrl}$ ), cadherin EGF LAG receptor 1b (flamingo), GPR64 and pituitary adenylate cyclase activating peptide (PACAP) type I receptor (adcyap1r1). Calcitonin receptor-like receptor has been shown to be co-expressed with RAMP1 in cortex, caudate putamen and olfactory tubercles, providing selective specificity to calcitonin gene-related peptide (CGRP) and regulation of endothelial cell proliferation [73]. Flamingo is a key receptor regulating dendritic net development in the retina and is also involved in axon guidance [74]. GPR64 is an orphan receptor, extensively expressed in epididymis, where it regulates fluid resorption from the ducts and when knocked-out in mice causes male infertility [75]. PACAP type 1 receptor is mainly expressed in the hypothalamus, where it regulates the release of a number of different hormones, including luteinizing hormone, growth hormone and prolactin, and stimulates proliferation of neuronal stem cells upon PACAP activation in mouse [76].

\section{Class III GPCRs - $\gamma$-Aminobutyric acid (GABA) B/metabotropic glutamate (mGluR) family}

The third class of GPCRs identified in olfactory epithelium, GABA (B) and mGluR receptor family includes Casensing receptor, taste receptors of the T1R family and putative pheromone V2R family [9]. The goldfish olfactory library contained ESTs encoding GABA(B) receptor 1 and putative pheromone receptors Cppr10, 11 and GFB 9 and 14 . The zebrafish collection contained additionally two homologues of cppr10, cppr1, V2R2 (GFB8), two homologues of GFB7, OR5.24 (gprc6a) and orphan gprc5c. In the rat olfactory bulb GABA-B receptors couple to Gai/ $o$ and stimulate an increase of cAMP via $\beta \gamma$-mediated acti- 
vation of adenylate cyclase 2 , while simultaneously inhibiting Gas-mediated activation of other adenylate cyclases [77].

The function of the two metabotropic glutamate receptor ESTs ( $m$ Glur 1 and $m$ Glur3) isolated is unclear but electrophysiological studies in the channel catfish indicated that they are directly involved in olfaction of glutamate [78]. Cpprs are putative pheromone receptors of unrevealed cyprinid species from the NCBI database. GFBs were isolated from goldfish, with numbers 9 and 14 represented by full-length cDNA sequences and the rest by partial protein fragments [11]. Odorant receptor 5.24 was first found in goldfish and is the only deorfanized receptor of this family with broad selectivity for positively charged amino acids. Mutagenesis studies of OR5.24 revealed inversion from positive to negative charge selectivity by some point mutations [79], the resulting modified sequence is present in related receptors suggesting they are candidate ORs for charged amino acid olfaction. GPRC5C is an orfan receptor from the mGluR family, which has been shown to be expressed under all-trans retinoic acid induction in peripheral tissues, although its function remains to be established [80].

\section{Progestin receptors in the olfactory epithelium}

As previously stated, goldfish and other cyprinids are able to smell progestin steroids, namely17,20ß-P and its sulphate and glucuronide conjugates which act as pre-ovulatory pheromones [81]. Physiological cross-adaptation studies of the olfactory epithelium suggest that there are at least two distinctive receptors, one shared by $17,20 \beta-\mathrm{P}$ and its glucuronide and the other for the sulphate [81]. Specific binding for 17,20ß-P has been found in olfactory epithelium membrane preparations using radio-receptor assays. [20]. In addition, pharmacological studies suggest that progestin signal transduction in the olfactory system acts via activation of the $G_{\alpha i}$ (pertussis toxin sensitive) proteins and consequent reduction of cAMP levels [19]. Overall, this physiological evidence is consistent with progestin pheromone receptors belonging to the GPCR family.

Possible candidates for progestin pheromone receptors are among the group of membrane progestin receptors (mPRs), which were first isolated from spotted seatrout (Cynoscion nebulosus) oocyte membranes [82] and, more recently, in other fish species, such as the zebrafish (Danio rerio), catfish (Ictalurus punctatus), medaka (Oryzias latipes) and goldfish (Carassius auratus) [83,84]. Homologous genes are also expressed in higher vertebrates, from frogs (Xenopus tropicalis) to rodents and humans [85]. These genes were identified as members of the progestin and AdipoQ receptor family (PAQR), an ancient group of GPCRs which has evolved from Eubacteria independent of other seven transmembrane domain receptors [86]. Three members of the PAQR family can bind progestins; PAQR7 (mPR $\alpha)$, PAQR8 (mPR $\beta)$ and PAQR5 (mPR $\gamma)$ [85]. As a result of fish specific duplication events, paralogous pairs of all three receptors have arisen. While, both mPR $\alpha$ and $\beta$ are products from intronless genes, mPR $\gamma$ is the product of a gene containing eight exons. Furthermore, each gene has distinctive tissue distribution patterns. While $\mathrm{mPR} \alpha$ and $\mathrm{mPR} \beta$ are mainly gonad and brain specific, $\mathrm{mPR} \gamma$ is expressed at higher levels in excretory tissues such as the intestine, colon, kidney and gills [83]. Functionally, they also play distinct roles. For example, mPR $\beta$ in ovaries is involved in vitellogenesis but not in final oocyte maturation, as its mRNA expression is unaffected by hormonal stimulation and sharply decreases at late vitellogenesis [87]. In the nervous system, $\operatorname{mPR} \beta$ expression is related to its role in mediating the stimulatory effects of progesterone in myelin sheath formation and initiation of neuro-protective gene expression $[88,89]$. In cell lines, $\mathrm{mPR} \beta$ has been shown to activate the MAP kinase signaling pathway and thereby to regulate gene expression but it has no apparent effect on $\mathrm{G}_{\alpha \mathrm{i}}$-mediated pathways [84].

The main functions of $\mathrm{mPR} \alpha$ in fish are related to reproduction; more specifically, to final oocyte or spermatozoa maturation. In goldfish and seatrout, its expression reaches a peak just prior to final maturation of the oocytes. This peak is necessary for maturation competence under gonadotrophin treatment mediated by the related

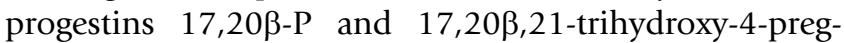
nen-3-one, respectively [90]. The latter progestin also acts via $\mathrm{mPR} \alpha$ to stimulate sperm motility in the Atlantic croaker Micropogonias undulatus [91]. In the zebrafish, activation of $\mathrm{mPR} \alpha$ inhibits adenylate cyclase activity, in a pertussis toxin sensitive manner, implying involvement of $\mathrm{G}_{\alpha \mathrm{i}}$. The functions of mPR $\gamma$ are still unclear, but it has been shown to bind progesterone and its hydroxylated derivatives in humans [85].

Genebank contains a number of cDNA for the mPR family and four gene products have been isolated from goldfish ovaries: mPR $\alpha$ (accession number $\underline{\mathrm{AB} 122087.1}$ ), mPR $\beta$ $(\underline{A B 284131.1}), \quad m P R \gamma-2$ (AB284133.1) and mPR $\gamma-1$ (AB284132.1). Zebrafish mPR $\alpha$ (AY149121.1) and mPR $\beta$ (AY149120.1) were reported by Zhu et al. [85] while two orthologues of mPR $\gamma-1$, PAQR5a (BC045864.1) and PAQR5b (BC078202.1), are part of the National Institutes of Health Mammalian Gene Collection [92]. $\mathrm{mPR} \gamma-2$ is a fish orthologue of mammalian PAQR6 and zebrafish 'LOC570587' (NW_001877690.1) was predicted from the genomic sequence.

In the present study several mPR receptors were identified in goldfish and zebrafish olfactory epithelia. In the 
zebrafish, a single EST for mPR $\beta$ and 11 ESTs encoding PAQR5b were identified. In contrast, the goldfish EST library did not contain any of these genes. However, other PAQR family members were identified; adiponectin receptors $1 \mathrm{~b}$ (adipor 1 ) and 2 (adipor 2 ) which are involved in lipid metabolism and PAQR3 (Raf kinase inhibitor) which prevents tumorogenesis [93]. RT-PCR studies with zebrafish olfactory epithelium and $\mathrm{MPR}$ specific primers revealed two splice variants of PAQR5b. In goldfish olfactory epithelium three different amplicons were obtained, a mPR $\gamma-1$ and two splice variants of $\mathrm{mPR} \gamma-2$. The presence of mPR $\beta$ was also confirmed by RT-PCR in the olfactory epithelium of both species, but it was not possible to amplify $\mathrm{mPR} \alpha$.

Further analysis of these mPR $\gamma$ transcripts revealed some interesting properties of one of the splice forms. Between the two paralogous genes, PAQR5a and PAQR5b, the latter is the closest orthologue to the goldfish $\mathrm{mPR} \gamma$ - 1 , with sequence similarity at both DNA and amino acid sequence levels of about $84 \%$ (Figure $3 \mathrm{~A}$ ). The PAQR5b gene product, isolated from the ovaries, is a transcript of the complete set of eight exons. One of the PCR products from the zebrafish olfactory epithelium represented exactly the same splice variant. Another PAQR5b PCR product and all 11 EST sequences from the zebrafish cDNA library are the result of alternative splicing, where exon number 5, a 15 amino acid fragment, is absent. The $\mathrm{mPR} \gamma-1$, reported earlier in ovaries and isolated in the current study from goldfish olfactory epithelium, lacks the same fragment (Figure 3B). ESTs of mPR $\gamma-1$ paralogue, containing exon 5, from other fish species are also available in GenBank: the phylogenetically distant stickleback (Gasterosteus aculeatus; e.g. DN666595), as well as other cyprinids such as the roach (Rutilus rutilus; EG532701) and fathead minnow (Pimephales promelas; DT191559). However, it was not possible to establish if the lack of exon 5 is a splice variant in goldfish or if this exon has been lost during evolution in this species.

Two other PCR products from goldfish were splice variants of $\mathrm{mPR} \gamma-2$. Whilst overall homology between protein sequence of $\mathrm{mPR} \gamma-2$ and PAQR $5 \mathrm{~b}$ was only $55 \%$, the amino acids on the borders of exons are well conserved and the gene organization of PAQR6 and PAQR5 is identical. This allowed alignment of PCR products against PAQR5b to establish exon composition and distinguish between splice variants and identify missing exons (Figure $3 \mathrm{~B})$. One of the PCR products amplified was identical to previously described $\mathrm{mPR} \gamma-2$ from ovaries. This transcript resembles $\mathrm{mPR} \gamma-1$ in that it also lacks exon 5. A novel splice variant was identified which lacks the relatively short exon 5 and the longer (33 amino acids) exon 6 (Figure 3B). Using a combination of SOSUI [94] and TMpred [95], the putative trans-membrane domain combinations for PAQR5b, mPR $\gamma$-2 (lacking exon 5) and mPR $\gamma$-2b (lacking exons 5 and 6) (Figure 4) was predicted. This analysis revealed that exon 5 encodes part of the second extra-cellular loop and its loss does not radically change the configuration of the trans-membrane domains. However, in the splice variant missing both exon 5 and 6 , complete rearrangement of trans-membrane domains 5 and 6 , as well as the third extra-cellular loop may occur (Figure 4C). We predict that the initial domain number 6 becomes inverted taking the place of the absent domain number 5 and that part of the long third extra-cellular loop, containing a low-score alpha helix, becomes the new domain 6 , preserving the stable seven trans-membrane architecture. Nevertheless, it is likely that such a drastic change in extracellular and trans-membrane architecture changes the ligand-binding properties and, possibly, the transduction pathway.

Screening of the NCBI EST database for the identified splice variants revealed a complete form of PAQR5b is expressed in the intestine, trunk kidney, colon, gills and gonads of fish. Single EST copies for the mPR $\gamma$-1-like splice variant were present in head kidney, skin and fins but the majority were located in zebrafish olfactory epithelium. mPR $\gamma-2$ was found only at low levels in the brain of zebrafish and the fathead minnow. However, in an ancient vertebrate, the sea lamprey (Petromyzon marinus), a single EST (EE741072.1) was identified for this receptor in the olfactory epithelium. In mammals, this receptor is expressed only in brain areas which have connections to the accessory olfactory bulb, suggesting a role in pheromonal signal processing. No sequence which lacked both exons 5 and 6 was identified in any sequence database and none of these genes were found in the mammalian olfactory system or in frog olfactory bulb.

Taken together, these results demonstrate the presence of several membrane-associated G-protein coupled receptors specific for progestin pheromones in the olfactory epithelium of goldfish and zebrafish. According to physiological and biochemical studies, GPCR pheromone receptors function via $\mathrm{G}_{\alpha \mathrm{i}}[20]$. As $\mathrm{mPR} \alpha$ was not identified in either species and activation of mPR $\beta$ does not decrease cAMP, $\mathrm{mPR} \gamma$ appears to be a good candidate for progestin-related signaling in the olfactory system. Several splice forms of the receptor were isolated in both species, one of which appears be unique to the goldfish olfactory epithelium, while another was over-represented in zebrafish olfactory epithelium compared to other tissues. The absence of $\mathrm{mPR} \gamma$ in the tetrapod olfactory system, its presence in early vertebrates and its affinity for hydroxyl-containing progesterone derivatives (but not estrogens, androgens or glucocorticoids) suggests a specific role for these gene products in detecting pheromonal progestins in some fish. In conclusion, we propose PAQR5 and PAQR6 
A)

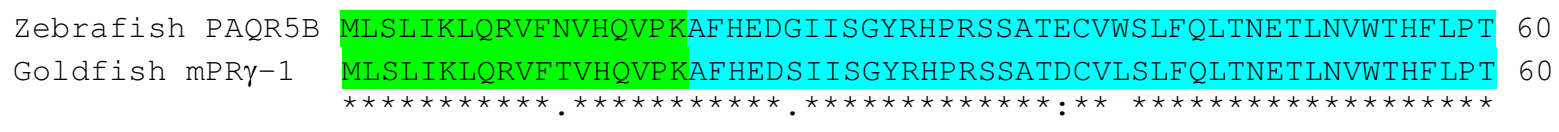

Zebrafish PAQR5B Goldfish mPR $\gamma-1$

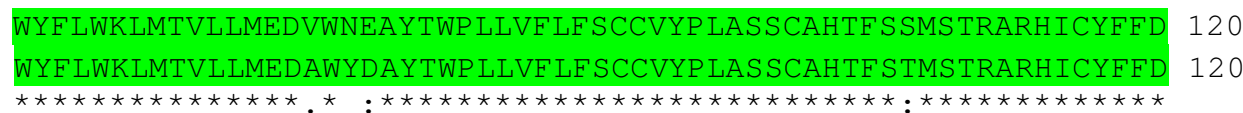

Zebrafish PAQR5B Goldfish $m P R \gamma-1$

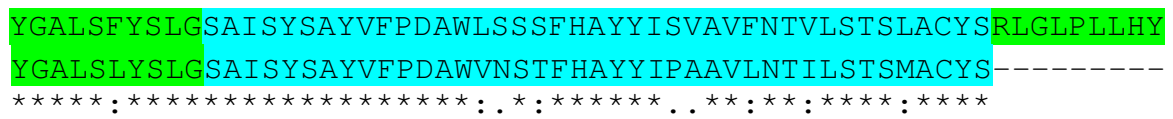

Zebrafish PAQR5B Goldfish mPR $\gamma-1$

Zebrafish PAQR5B Goldfish mPR $\gamma-1$

Zebrafish PAQR5B Goldfish mPR $\gamma-1$
180 171
TLLAF LTSF LFATHLPERLAP GRFDY I GHSHQLF HVCA I I GTHFQMKA IEMDMGLRRSQL TLLAF LTAF LFATHLPERLAP GCFDY I GHSHQLFHVCA I I GTHFQMKA IEADMVLRQSQL

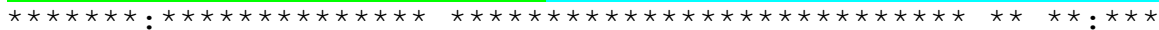

LASAPA ISFNNTIGAALLCVSVSLGI I CVYSLPLLYSSNPKNTANKE*------ 347 LVTAPPITFNNTVGSAPVCVCISLGIICLYSLPLLYGSSETHTTRTEGKKCKH* 338

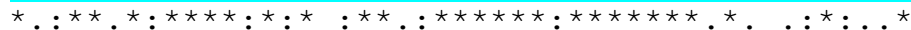

\section{0}

120

\section{B)}

Goldfish mPR $\gamma-2 \mathrm{~b}$ Goldfish mPR $\gamma-2$ Zebrafish PAQR5B

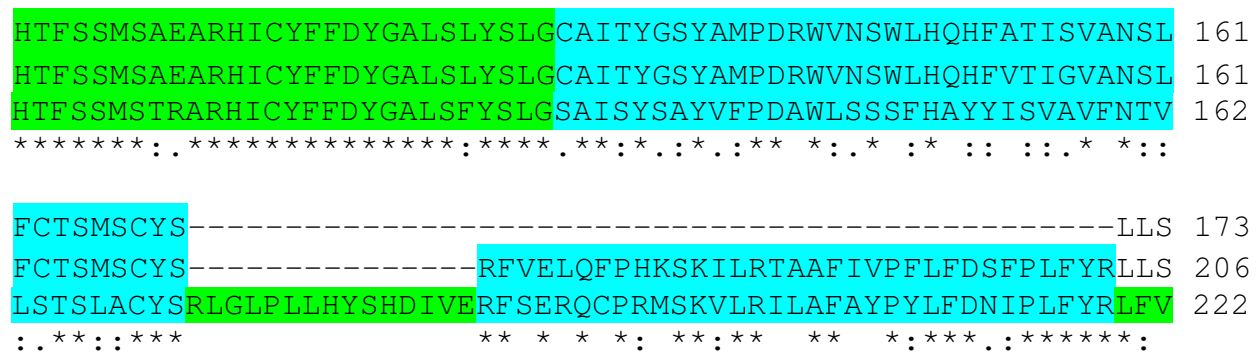

Goldfish mPR $\gamma-2 \mathrm{~b}$ Goldfish mPR $\gamma-2$ Zebrafish PAQR5B

Goldfish mPR $\gamma-2 \mathrm{~b}$ Goldfish mPR $\gamma-2$ Zebrafish PAQR5B

\section{Figure 3}

Alignment of membrane progestin receptor splice variants from the fish olfactory epithelium. Exon composition of PAQR5b and mPR $\gamma-I$ (A, alternating colours) and alignment of two mPR $\gamma-2$ splice variants from goldfish olfactory epithelium (B, colours represent corresponding exons 5 and 6 in PAQR5b).

(mPR $\gamma-1$ and mPR $\gamma-2$ in goldfish) as progestin pheromone receptors in cyprinids. However, further studies are necessary to confirm or discard this hypothesis.

\section{Conclusion}

Through comparisons and combination of the goldfish olfactory epithelium ESTs produced in this study with those available for zebrafish it was possible to estimate that the olfactory epithelium transcriptome contain around 16,400 unigenes and to identify a number of nerv- 
A) PAQR5B

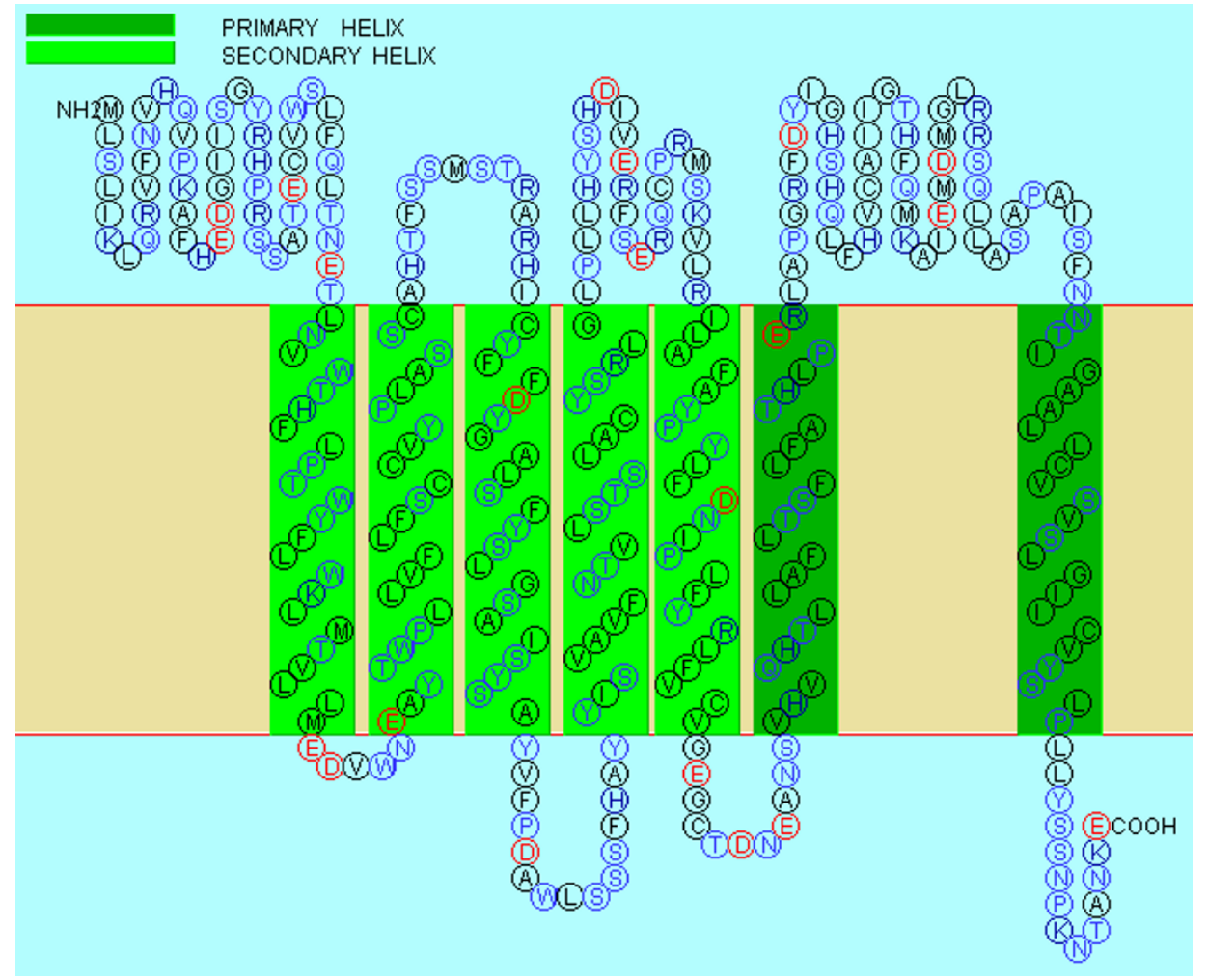

B)

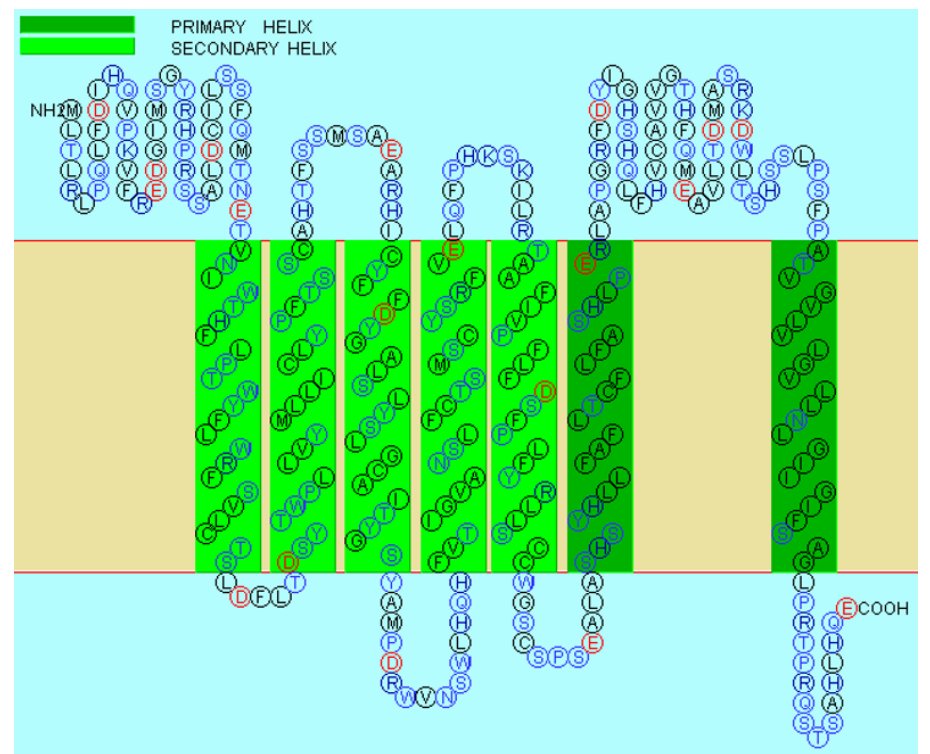

C) mPRgamma2b

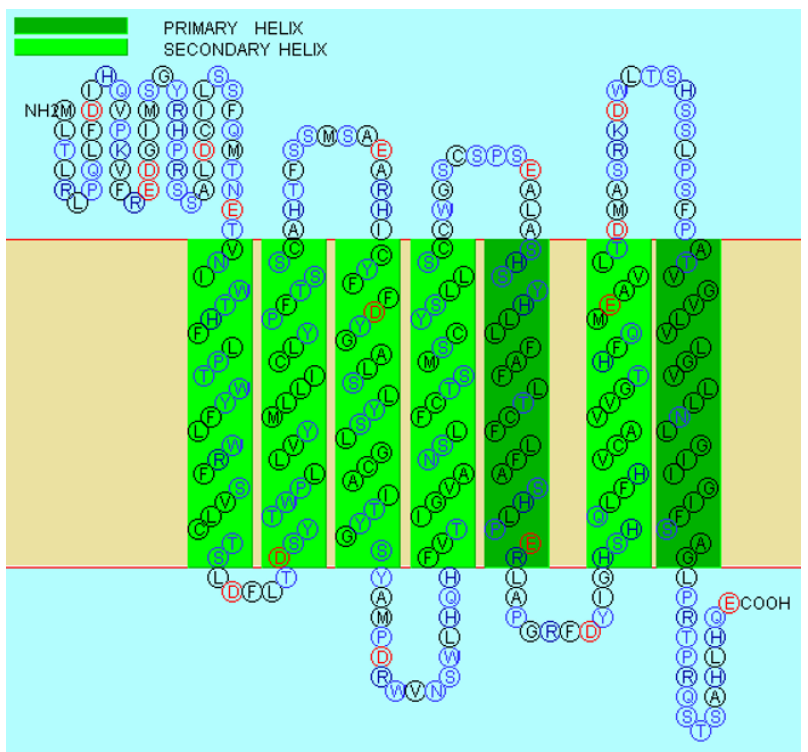

Figure 4

Predicted secondary structure of membrane progestin receptors from the fish olfactory epithelium. Snake-plot of complete PAQR5b and two mPR $\gamma-2$ splice variants from fish olfactory epithelia built using SOSUI prediction. Note that TM architecture remains despite significant rearrangement of transmembrane helices in case of $\mathrm{mPR} \gamma 2 \mathrm{~b}$. 
ous tissue markers and several elements of signalling pathways involved in olfaction. For example, 124 GPCRs were identified and included receptors for cytokines, neurotransmitters, growth and development factors, hormones, steroids and olfactory cues.

The presence of a large number of immune system genes may reflect the epithelial character of the tissue and also the necessity for tight control on intensive processes such as, regeneration of the neuron population which involves cytokines and immune cells. Hormonal receptors also help us to understand regulatory mechanisms involved in the functioning and precise adjustment of the olfactory system. Growth factor receptors provide an important tool for developing selective markers for the different cell types composing this complex tissue and to study processes involved in differentiation of sensory neurons. The TAAR receptors found in the goldfish olfactory library were not as diverse as expected from genomic prediction and expression studies in zebrafish, raising the possibility of species-specific adaptations in the olfactory system.

One third of the GPCR repertoire was classical ORs and indicates that fish probably recognize a wide variety of potential odorants. While most ORs remain orphans, two subfamilies were linked to specific amino acid subclasses, long-chain non polar and charged. Receptors known to bind nucleotides were also identified. We have estimated that the repertoire of Class A ORs expressed in the olfactory epithelium in cyprinids to be between 45 and 50 and confirmed this with RT-PCR. Similarly 40-45 TAARs are estimated to be expressed.

Finally we have identified four members of the membrane progestin receptor family. Three of them fit the criteria of possible candidates for main elements in steroid pheromone communication. Namely, they are diverse splice variants of two closely related paralogues of fish maturation inducing-steroid receptors; they demonstrate an olfactory system specific profile of expression in fish; and they are predicted to bind Gai, which is known to mediate the progestin olfactory response in goldfish. Taken together we suggest that the group of PAQR5 and PAQR6 gene products could be pheromone receptors in fish, although further studies such as, histochemical and cell culture expression are needed.

\section{Materials and methods Isolation of olfactory epithelia}

The goldfish used in this study were obtained from a local pet shop. Fish were anesthetized with MS222 and olfactory tissue was dissected out and placed in liquid nitrogen. Twenty normal body shaped specimens of $10-15 \mathrm{~cm}$ and 20-25 g and of both sexes were used.

\section{Preparation of a cDNA library}

Total RNA was extracted with Tri Reagent and treated with DNAse. mRNA purification and concentration were performed using Dynal's oligo-dT magnetic beads. The normalized olfactory epithelium cDNA library was constructed using cDNA SMART-kit (Clontech) and thermostable duplex-specific nuclease [96]. Sequencing was carried out at the Max Planck Institute of Molecular Genetics (Berlin, Germany) using a Capillary Sequencer systems, ABI 3730 XL (Applied Biosystems) and MegaBase 4500 (GE Healthcare, formally Amersham-Pharmacia) and all sequencing reactions were carried out with $A B I$ BigDye Terminator version 3.1. All the EST sequences were deposited by dbEST in EMBL http://www.ebi.ac.uk/ embl/ under accession numbers AM925430... AM930226.

\section{Computational methods}

The DNA sequence chromatograms were analyzed using the Phred software [97] for base call and for estimation of error probability at the Max Planck Institute of Molecular Genetics. All sequences were edited to remove ribosomal RNA, polyA tails, low-quality sequences, and vector and adapter regions. Cross-comparison using Liru local blast software was carried out and sequences with more than 95\% identity were assembled manually. The resulting contigs and singletons were assessed for similarity to the protein non-redundant database using BlastX at NCBI [98] and sequences annotated if the match complied with the following criteria: e-value $<\mathrm{e}^{-10}$ and $>70 \%$ of alignment coverage, or $\mathrm{e}^{-40}$ if only the $3^{\prime}$ UTR matched the database. Gene ontology (GO) and Genecards websites were used for functional annotation of identified genes. All annotations and GO assignments were curated manually. To compare GO category counts the WeGo interface was used [99]. The Gene Ontology category selected as a basis for transcriptome size estimation was the Glucose Metabolic Process (GO:0006006). To evaluate the number of orthologous genes present in the library and estimate transcriptome size, a side to side unigene set comparison was performed against zebrafish olfactory epithelium libraries. The libraries used were obtained from NCBI database Unigene [100], dbEST 2387 "Zebrafish adult olfactory" from Washington University School of Medicine and dbEST "NIH_ZGC_14" from National Institutes of Health, Zebrafish Gene Collection. Because none of the libraries were normalized, as indicated in the data annotation, they were pooled together with summation of counts for each unigene present in both of them. All genes, mentioned in the article, were identified from ESTs or amplified by RT-PCR in one or both fish species olfactory epithelium. Alignments were carried out using ClustalW interface at EBI http://www.ebi.ac.uk/Tools/ clustalw2/. 


\section{RT-PCR amplification of olfactory receptors and PAQRs}

Total RNA was extracted with Tri Reagent from the olfactory epithelium of 15 goldfish or zebrafish of both sexes at different seasons. Samples were treated with DNAse (Quiagen). Specific primers for each family of GPCR Class A were designed using conserved gene regions identified by multiple alignment of available olfactory receptors from teleost fish species. Primers for PAQR genes were based on sequences from published goldfish sequences (indicated above). Primers used were: $\mathrm{mPR} \gamma 12$ forwardCACACCTTCAGCACCATGTC; mPR $\gamma$ 12reverse - TCCAGGTGCCAGTCTCTC; $\mathrm{mPR} \alpha \beta$ forward-TGTGTGGACACACCTGCTGGC; $\operatorname{mPR} \alpha \beta \quad$ reverseGTACAGGACAGCCAGGCCAGGA. Amplification was performed using a MyCycler (BioRad) thermocycler with conditions adjusted for each primer pair. The PCR products were cloned in pGem-T-Easy and sequenced in both directions with T7 and SP6 primers using a 3130x sequencer (Applied Biosystems).

\section{Authors' contributions}

NK collected the samples, planned the work, carried out the EST analysis and wrote the manuscript; MK produced and sequenced the goldfish cDNA library; RR contributed with funds and the sequencing platform; AVMC planned the work, provided funds and wrote the manuscript;

\section{Additional material}

\section{Additional file 1}

List of annotated goldfish expressed sequence tags. The data provided represent the manually curated annotated list of goldfish EST.

Click here for file

[http://www.biomedcentral.com/content/supplementary/14712164-9-429-S1.xls]

\section{Acknowledgements}

The authors acknowledge the excellent technical assistance from Alfred Beck, Heiner Kuhl and Sven Klages and the financial support of the European Commission through the Network of Excellence Marine Genomics Europe (project code GOCE-CT-2004-505403). We also would like to thank Dr. Deborah M. Power and Dr. Peter C. Hubbard for helpful discussions and for revising the manuscript. NK was funded by the Portuguese National Science Foundation and European Social Funds fellowship (SFRH/ $\mathrm{BD} / 12736 / 20043)$.

\section{References}

I. Kotrschal K: Taste(s) and olfaction(s) in fish: a review of spezialized sub-systems and central integration. Pflugers Arch Eur J Physiol 2000, 439(7): r I 78-rl80.

2. Hara TJ: Feeding behaviour in some teleosts is triggered by single amino acids primarily through olfaction. J Fish Biol 2006, 68(3):810-825.

3. Carreau ND, Pyle GG: Effect of copper exposure during embryonic development on chemosensory function of juvenile fathead minnows (Pimephales promelas). Ecotox Environ Safe 2005, 6 I (I): I-6.
4. Hidaka $\mathrm{H}$, Tatsukawa $\mathrm{R}$ : Avoidance by olfaction in a fish, medaka (Oryzias latipes), to aquatic contaminants. Environ Pollut 1989, 56(4):299-309.

5. Blechinger SR, Kusch RC, Haugo K, Matz C, Chivers DP, Krone PH: Brief embryonic cadmium exposure induces a stress response and cell death in the developing olfactory system followed by long-term olfactory deficits in juvenile zebrafish. Toxicol Appl Pharm 2007, 224(I):72-80.

6. Saglio $\mathrm{P}$, Olsén $\mathrm{KH}$, Bretaud $\mathrm{S}$ : Behavioral and olfactory responses to prochloraz, bentazone, and nicosulfuron-contaminated flows in goldfish. Arch Environ Con Tox 200I, 4I(2): I 92-200.

7. Buck $L$, Axel R: A novel multigene family may encode odorant receptors - a molecular basis for odor recognition. Cell I99I, 65(I): $175-187$.

8. Alioto TS, Ngai J: The odorant receptor repertoire of teleost fish. BMC Genomics 2005, 6(173): I73.

9. Alioto TS, Ngai J: The repertoire of olfactory $\mathbf{C}$ family $\mathbf{G}$ protein-coupled receptors in zebrafish: candidate chemosensory receptors for amino acids. BMC Genomics 2006, 7(309):309.

10. Kime DE: 'Classical' and 'non-classical' reproductive steroids in fish. Rev Fish Biol Fish 1993, 3(2): 160-180.

II. Cao YX, Oh BC, Stryer L: Cloning and localization of two multigene receptor families in goldfish olfactory epithelium. $P$ Natl Acad Sci USA 1998, 95(20): I I 987-I 1992.

12. Speca DJ, Lin DM, Sorensen PW, Isacoff EY, Ngai J, Dittman AH: Functional identification of a goldfish odorant receptor. Neuron 1999, 23(3):487-498.

13. Freitag J, Ludwig G, Andreini I, Rossler P, Breer H: Olfactory receptors in aquatic and terrestrial vertebrates. J Comp Physiol $[A]$ 1998, I 83(5):635-650.

14. Rolen SH, Sorensen PW, Mattson D, Caprio J: Polyamines as olfactory stimuli in the goldfish Carassius auratus. J Exp Biol 2003, 206(Pt I0): I683-1696

15. Hara TJ: Olfaction and gustation in fish - an overview. Acta Physiol Scand 1994, I 52(2):207-2I7.

16. Poling KR, Fraser EJ, Sorensen PW: The three steroidal components of the goldfish preovulatory pheromone signal evoke different behaviors in males. Comp Biochem Phys B 2001, I 29(23):645-65I.

17. Sorensen PW, Pinillos M, Scott AP: Sexually mature male goldfish release large quantities of androstenedione into the water where it functions as a pheromone. Gen Comp Endocrinol 2005, I40(3): 164-175.

18. Sorensen PW, Hara TJ, Stacey NE, Goetz FW: F prostaglandins function as potent olfactory stimulants that comprise the postovulatory female sex pheromone in goldfish. Biol Reprod 1988, 39(5): 1039-1050.

19. Sorensen PW, Sato K: Second messenger systems mediating sex pheromone and amino acid sensitivity in goldfish olfactory receptor neurons. Chem Senses 2005, 30(suppl_I):i3 I 5-3 I6.

20. Rosenblum PM, Sorensen PW, Stacey NE, Peter RE: Binding of the steroidal pheromone I $7 \alpha, 20 \beta$-dihydroxy-4-pregnen-3-one to goldfish (Carassius auratus) olfactory epithelium membrane preparations. Chem Senses 1991, I6(2):143-154.

21. Tatake RJ, Ferrone S, Zeff RA: The role of beta-2 microglobulin in temperature-sensitive and interferon-gamma-induced exocytosis of HLA class I molecules. Transplantation 1992 , 54(3):395-403.

22. Wu KJ, Polack A, Dalla-Favera R: Coordinated regulation of ironcontrolling genes, $\mathrm{H}$-ferritin and IRP2, by c-MYC. Science 1999, 283(5402):676-679.

23. Arcuri F, Papa S, Carducci A, Romagnoli R, Liberatori S, Riparbelli MG, Sanchez JC, Tosi P, del Vecchio MT: Translationally controlled tumor protein (TCTP) in the human prostate and prostate cancer cells: expression, distribution, and calcium binding activity. Prostate 2004, 60(2): I30-140.

24. Barrallo A, Gonzalez-Sarmiento R, Garcia-Isidoro M, Cidad P, Porteros A, Rodriguez RE: Differential brain expression of a new beta-actin gene from zebrafish (Danio rerio). Eur J Neurosci 1999, I I (I):369-372.

25. Beffert U, Danik M, Krzywkowski P, Ramassamy C, Berrada F, Poirier $\mathrm{J}$ : The neurobiology of apolipoproteins and their receptors in the CNS and Alzheimer's disease. Brain Res Brain Res Rev 1998 , 27(2): I 19-142. 
26. Abdel-Malek Z, Swope V, Collins C, Boissy R, Zhao H, Nordlund J: Contribution of melanogenic proteins to the heterogeneous pigmentation of human melanocytes. J Cell Sci 1993, I06(Pt 4): |323-|33|.

27. Hermanto U, Zong CS, Li W, Wang L-H: RACKI, an insulin-like growth factor I (IGF-I) receptor-interacting protein, modulates IGF-I-dependent integrin signaling and promotes cell spreading and contact with extracellular matrix. Mol Cell Biol 2002, 22(7):2345-2365.

28. Li P, Peatman E, Wang S, Feng J, He C, Baoprasertkul P, Xu P, Kucuktas H, Nandi S, Somridhivej B, et al.: Towards the ictalurid catfish transcriptome: generation and analysis of 3I,2I5 catfish ESTs. BMC Genomics 2007, 8(I): 177.

29. Raport CJ, Gosling J, Schweickart VL, Gray PW, Charo IF: Molecular cloning and functional characterization of a novel human $C C$ chemokine receptor (CCR5) for RANTES, MIP-I $\beta$, and MIP. I $\alpha$. J Biol Chem 1996, 27I(29): I7161-17166.

30. Krzysiek R, Lefevre EA, Bernard J, Foussat A, Galanaud P, Louache F, Richard Y: Regulation of CCR6 chemokine receptor expression and responsiveness to macrophage inflammatory protein-3 $\alpha /$ CCL20 in human B cells. Blood 2000, 96(7):2338-2345.

31. Lasagni L, Francalanci M, Annunziato F, Lazzeri E, Giannini S, Cosmi L, Sagrinati C, Mazzinghi B, Orlando C, Maggi E, et al.: An alternatively spliced variant of CXCR3 mediates the inhibition of endothelial cell growth induced by IP-I0, Mig, and I-TAC and acts as functional receptor for platelet factor 4. J Exp Med 2003, I97( I I): I 537-I549.

32. Khan MZ, Brandimarti R, Musser BJ, Resue DM, Fatatis A, Meucci O The chemokine receptor $C X C R 4$ regulates cell-cycle proteins in neurons. J Neurovirol 2003, 9(3):300-3।4.

33. Miyasaka N, Knaut H, Yoshihara Y: Cxcl I 2/Cxcr4 chemokine signaling is required for placode assembly and sensory axon pathfinding in the zebrafish olfactory system. Development 2007, I34(13):2459-2468.

34. Infantino S, Moepps B, Thelen M: Expression and regulation of the orphan receptor RDCI and its putative ligand in human dendritic and B cells. J Immunol 2006, I 76(4):2197-2207.

35. Legler DF, Loetscher M, Roos RS, Clark-Lewis I, Baggiolini M, Moser B: B cell-attracting chemokine I, a human CXC chemokine expressed in lymphoid tissues, selectively attracts B lymphocytes via BLRI/CXCR5. J Exp Med I998, I 87(4):655-660.

36. Radu CG, Yang LV, Riedinger M, Au M, Witte ON: T cell chemotaxis to lysophosphatidylcholine through the G2A receptor. Proc Natl Acad Sci USA 2004, I 0 I ( I):245-250.

37. Sugo $T$, Tachimoto $H$, Chikatsu $T$, Murakami $Y$, Kikukawa $Y$, Sato $S$, Kikuchi K, Nagi T, Harada M, Ogi K, et al.: Identification of a lysophosphatidylserine receptor on mast cells. Biochem Biophys Res Commun 2006, 34 I(4): I078-1087.

38. Van Brocklyn JR, Tu Z, Edsall LC, Schmidt RR, Spiegel S: Sphingosine I-phosphate-induced cell rounding and neurite retraction are mediated by the $\mathbf{G}$ protein-coupled receptor $\mathbf{H 2}$ I 8 . J Biol Chem I999, 274(8):4626-4632.

39. Kawasawa $Y$, Kume K, Nakade S, Haga H, Izumi T, Shimizu T: Brainspecific expression of novel G-protein-coupled receptors, with homologies to Xenopus PSP24 and human GPR45. Biochem Biophys Res Commun 2000, 276(3):952-956.

40. Niedernberg A, Tunaru S, Blaukat A, Ardati A, Kostenis E: Sphingosine I-phosphate and dioleoylphosphatidic acid are low affinity agonists for the orphan receptor GPR63. Cell Signal 2003 , I 5(4):435-446

4I. Kamohara M, Takasaki J, Matsumoto M, Saito T, Ohishi T, Ishii H, Furuichi K: Molecular cloning and characterization of another leukotriene B4 receptor. J Biol Chem 2000, 275(35):27000-27004.

42. Tan CP, McKee KK, Liu Q, Palyha OC, Feighner SD, Hreniuk DL, Smith RG, Howard AD: Cloning and characterization of a human and murine T-cell orphan G-protein-coupled receptor similar to the growth hormone secretagogue and neurotensin receptors. Genomics I998, 52(2):223-229.

43. Birkenbach M, Josefsen K, Yalamanchili R, Lenoir G, Kieff E: EpsteinBarr virus-induced genes: first lymphocyte-specific $G$ protein-coupled peptide receptors. J Virol 1993, 67(4):2209-2220.

44. Bhute $\mathrm{YV}$, Baile $\mathrm{VV}$ : Organization of the olfactory system of the Indian major carp Labeo rohita (Ham.): A scanning and transmission electron microscopy study. J Evol Biochem Physiol 2007, 43(3):342-349.
45. Tran PB, Miller RJ: Chemokine receptors: Signposts to brain development and disease. Nat Rev Neurosci 2003, 4(6):444-455.

46. Julliard AK, Saucier D, Astic L: Time-course of apoptosis in the olfactory epithelium of rainbow trout exposed to a low copper level. Tissue Cell 1996, 28(3):367-377.

47. Storch MK, Weissert R, Stefferl A, Birnbacher R, Wallstrom E, Dahlman I, Ostensson CG, Linington C, Olsson T, Lassmann H: MHC gene related effects on microglia and macrophages in experimental autoimmune encephalomyelitis determine the extent of axonal injury. Brain Pathol 2002, I 2(3):287-299.

48. Ralevic V, Burnstock G: Receptors for purines and pyrimidines. Pharmacol Rev 1998, 50(3):4I 3-492.

49. Kim C-H, Kim S-S, Choi JY, Shin J-H, Kim JY, Namkung W, Lee J-G, Lee MG, Yoon J-H: Membrane-specific expression of functional purinergic receptors in normal human nasal epithelial cells. Am J Physiol Lung Cell Mol Physiol 2004, 287(4):L835-842.

50. Hegg CC, Greenwood D, Huang W, Han P, Lucero MT: Activation of purinergic receptor subtypes modulates odor sensitivity. J Neurosci 2003, 23(23):8291-8301

51. Nikonov AA, Caprio J: Electrophysiological evidence for a chemotopy of biologically relevant odors in the olfactory bulb of the channel catfish. J Neurophysiol 200I, 86(4): | 869- I876.

52. Bouchelet I, Cohen Z, Case B, Seguela P, Hamel E: Differentia expression of sumatriptan-sensitive 5-hydroxytryptamine receptors in human trigeminal ganglia and cerebral blood vessels. Mol Pharmacol 1996, 50(2):219-223.

53. Zucchi R, Chiellini G, Scanlan TS, Grandy DK: Trace amine-associated receptors and their ligands. $\mathrm{Br} J$ Pharmacol 2006, I 49(8):967-978.

54. Liberles SD, Buck LB: A second class of chemosensory receptors in the olfactory epithelium. Nature 2006, 442(7 I 03):645-650.

55. Gloriam DE, Bjarnadottir TK, Yan YL, Postlethwait JH, Schioth HB, Fredriksson R: The repertoire of trace amine G-protein-coupled receptors: large expansion in zebrafish. Mol Phylogenet Evol 2005, 35(2):470-482.

56. Berghard A, Dryer L: A novel family of ancient vertebrate odorant receptors. J Neurobiol 1998, 37(3):383-392.

57. Hubbard PC, Barata EN, Canario AVM: Olfactory sensitivity to catecholamines and their metabolites in the goldfish. Chem Senses 2003, 28(3):207-218.

58. Mano M, Arakawa T, Mano H, Nakagawa M, Kaneda T, Kaneko $\mathrm{H}$, Yamada T, Miyata K, Kiyomura H, Kumegawa M, et al.: Prostaglandin E2 directly inhibits bone-resorbing activity of isolated mature osteoclasts mainly through the EP4 receptor. Calcif Tissue Int 2000, 67(I):85-92.

59. Mori K, Tanaka I, Kotani M, Miyaoka F, Sando T, Muro S, Sasaki Y, Nakagawa O, Ogawa Y, Usui T, et al.: Gene expression of the human prostaglandin E receptor EP4 subtype: differential regulation in monocytoid and lymphoid lineage cells by phorbol ester. J Mol Med 1996, 74(6):333-336.

60. Arakawa T, Laneuville O, Miller CA, Lakkides KM, Wingerd BA, DeWitt DL, Smith WL: Prostanoid Receptors of Murine NIH 3T3 and RAW 264.7Cells. Structure and expression of the murine prostaglandin EP4 receptor gene. J Biol Chem 1996, 27 I(47):29569-29575.

61. Breit A, Lagace M, Bouvier M: Hetero-oligomerization between $\beta_{2}$-and $\beta_{3}$-adrenergic receptors generates a $\beta$-adrenergic signaling unit with distinct functional properties. I Biol Chem 2004, 279(27):28756-28765.

62. Minneman KP: Heterodimerization and surface localization of G protein coupled receptors. Biochem Pharmacol 2007 73(8): $1043-1050$

63. Hague C, Uberti MA, Chen Z, Bush CF, Jones SV, Ressler KJ, Hall RA, Minneman KP: Olfactory receptor surface expression is driven by association with the $\beta_{2}$-adrenergic receptor. $P$ Natl Acad SCi USA 2004, I0 I(37): I3672-13676.

64. Roesler R, Henriques JA, Schwartsmann G: Gastrin-releasing peptide receptor as a molecular target for psychiatric and neurological disorders. CNS Neurol Disord Drug Targets 2006, 5(2): $197-204$

65. Kubo A, Fukui $\mathrm{H}$, Inagaki $\mathrm{N}$, Kanamura A, Wada $\mathrm{H}$ : Histamineinduced cyclic AMP accumulation in type- I and type-2 astrocytes in primary culture. Eur J Pharmacol I99I, 208(3):249-253.

66. Rossier O, Cao J, Huque T, Spielman Al, Feldman RS, Medrano JF, Brand JG, le Coutre J: Analysis of a human fungiform papillae 
cDNA library and identification of taste-related genes. Chem Senses 2004, 29(I):13-23.

67. Vanti WB, Nguyen T, Cheng R, Lynch KR, George SR, O'Dowd BF: Novel human G-protein-coupled receptors. Biochem Biophys Res Commun 2003, 305(I):67-7I.

68. Raming K, Konzelmann S, Breer H: Identification of a novel Gprotein coupled receptor expressed in distinct brain regions and a defined olfactory zone. Receptors Channels 1998, 6(2): $|4|-|5|$.

69. Matsumoto M, Saito T, Takasaki J, Kamohara M, Sugimoto T, Kobayashi M, Tadokoro M, Matsumoto S, Ohishi T, Furuichi K: An evolutionarily conserved G-protein coupled receptor family, SREB, expressed in the central nervous system. Biochem Biophys Res Commun 2000, 272(2):576-582.

70. Mezler M, Fleischer J, Breer $\mathrm{H}$ : Characteristic features and ligand specificity of the two olfactory receptor classes from Xenopus laevis. J Exp Biol 200I, 204( I 7):2987-2997.

7I. Singer MS, Oliveira L, Vriend G, Shepherd GM: Potential ligandbinding residues in rat olfactory receptors identified by correlated mutation analysis. Receptors Channels 1995, 3(2):89-95.

72. Hashiguchi $Y$, Nishida M: Evolution of trace amine associated receptor (TAAR) gene family in vertebrates: Lineage-specific expansions and degradations of a second class of vertebrate chemosensory receptors expressed in the olfactory epithelium. Mol Biol Evol 2007, 24(9):2099-2I 07

73. Oliver KR, Kane SA, Salvatore CA, Mallee JJ, Kinsey AM, Koblan KS, Keyvan-Fouladi N, Heavens RP, Wainwright A, Jacobson M, et al: Cloning, characterization and central nervous system distribution of receptor activity modifying proteins in the rat. Eur J Neurosci 200I, I4(4):618-628.

74. Ghosh A: Dentritic growth: Don't go says flamingo. Neuron 2000, 28(I):3-4.

75. Davies B, Baumann C, Kirchhoff C, Ivell R, Nubbemeyer R, Habenicht UF, Theuring F, Gottwald U: Targeted deletion of the epididymal receptor HE6 results in fluid dysregulation and male infertility. Mol Cell Biol 2004, 24(19):8642-8648.

76. Mercer A, Rönnholm H, Holmberg J, Lundh H, Heidrich J, Zachrisson O, Ossoinak A, Frisén J, Patrone C: PACAP promotes neural stem cell proliferation in adult mouse brain. J Neurosci Res 2004, 76(2):205-2I5.

77. Olianas MC, Onali P: GABA(B) receptor-mediated stimulation of adenylyl cyclase activity in membranes of rat olfactory bulb. Br J Pharmacol 1999, I 26(3):657-664.

78. Medler KF, Tran HN, Parker JM, Caprio J, Bruch RC: Metabotropic glutamate receptor expression in olfactory receptor neurons from the channel catfish, Ictalurus punctatus. J Neurobiol 1998, 35(I):94-104.

79. Kuang DH, Yao Y, Wang MH, Pattabiraman N, Kotra LP, Hampson DR: Molecular similarities in the ligand binding pockets of an odorant receptor and the metabotropic glutamate receptors. I Biol Chem 2003, 278(43):4255 I -42559.

80. Robbins MJ, Michalovich D, Hill J, Calver AR, Medhurst AD, Gloger I, Sims M, Middlemiss DN, Pangalos MN: Molecular cloning and characterization of two novel retinoic acid-inducible orphan G-protein-coupled receptors (GPRC5B and GPRC5C). Genomics 2000, 67(I):8-18.

81. Sorensen PW, Scott AP, Stacey NE, Bowdin L: Sulfated 17,20ßdihydroxy-4-pregnen-3-one functions as a potent and specific olfactory stimulant with pheromonal actions in the goldfish. Gen Comp Endocrinol 1995, I00(I): 128-142.

82. Zhu Y, Rice CD, Pang Y, Pace M, Thomas P: Cloning, expression, and characterization of a membrane progestin receptor and evidence it is an intermediary in meiotic maturation of fish oocytes. Proc Natl Acad Sci USA 2003, 100(5):223I-2236.

83. Kazeto Y, Goto-Kazeto R, Thomas P, Trant JM: Molecular characterization of three forms of putative membrane-bound progestin receptors and their tissue-distribution in channel catfish, Ictalurus punctatus. J Mol Endocrinol 2005, 34(3):78I-79I.

84. Hanna R, Pang $Y$, Thomas $P$, Zhu $Y$ : Cell-surface expression, progestin binding, and rapid nongenomic signaling of zebrafish membrane progestin receptors $\alpha$ and $\beta$ in transfected cells. IEndocrinol 2006, I 90(2):247-260.

85. Zhu Y, Bond J, Thomas P: Identification, classification, and partial characterization of genes in humans and other vertebrates homologous to a fish membrane progestin receptor. Proc Natl Acad Sci USA 2003, 100(5):2237-2242.
86. Tang YT, Hu T, Arterburn M, Boyle B, Bright JM, Emtage PC, Funk WD: PAQR proteins: a novel membrane receptor family defined by an ancient 7-transmembrane pass motif. $J \mathrm{Mol}$ Evol 2005, 6 I (3):372-380.

87. Mourot B, Nguyen T, Fostier A, Bobe J: Two unrelated putative membrane-bound progestin receptors, progesterone membrane receptor component I (PGMRCI) and membrane progestin receptor ( $\mathrm{mPR}) \beta$, are expressed in the rainbow trout oocyte and exhibit similar ovarian expression patterns. Reprod Biol Endrocinol 2006, 4(I):6.

88. Schumacher M, Guennoun R, Robert F, Carelli C, Gago N, Ghoumar A, Gonzalez Deniselle MC, Gonzalez SL, Ibanez C, Labombarda F, et al.: Local synthesis and dual actions of progesterone in the nervous system: neuroprotection and myelination. Growth Horm IGF Res 2004, 14(Supplement I): I8-33.

89. Sakamoto $H$, Ukena K, Tsutsui K: Activity and localization of $3 \beta$ hydroxysteroid dehydrogenase- $\Delta 5-\Delta 4$ isomerase in the zebrafish central nervous system. I Comp Neurol 200I, 439(3):291-305.

90. Thomas P, Pinter J, Das S: Upregulation of the maturationinducing steroid membrane receptor in spotted seatrout ovaries by gonadotropin during oocyte maturation and its physiological significance. Biol Reprod 200I, 64(I):2I-29.

91. Thomas P, Tubbs C, Detweiler C, Das S, Ford L, Breckenridge-Miller $D$ : Binding characteristics, hormonal regulation and identity of the sperm membrane progestin receptor in Atlantic croaker. Steroids 2005, 70(5-7):427-433.

92. MGC, Strausberg RL, Feingold EA, Grouse LH, Derge JG, Klausner RD, Collins FS, Wagner L, Shenmen CM, Schuler GD, et al:: Generation and initial analysis of more than 15,000 full-length human and mouse cDNA sequences. P Natl Acad Sci USA 2002, 99(26): 16899-16903.

93. Fan $F$, Feng $L$, He J, Wang $X$, Jiang $X$, Zhang $Y$, Wang $Z$, Chen $Y$ : RKTG sequesters $B-R a f$ to the Golgi apparatus and inhibits the proliferation and tumorigenicity of human malignant melanoma cells. Carcinogenesis 2008, 29(6): I I57-II63.

94. Hirokawa T, Boon-Chieng S, Mitaku S: SOSUI: classification and secondary structure prediction system for membrane proteins. Bioinformatics 1998, 14(4):378-379.

95. Hofmann K, Stoffel W: TMbase - A database of membrane spanning proteins segments. Biol Chem 1993, 374:166.

96. Zhu YY, Machleder EM, Chenchik A, Li R, Siebert PD: Reverse transcriptase template switching: a SMART approach for fulllength cDNA library construction. Biotechniques 200I, 30(4):892-897.

97. Ewing B, Hillier L, Wendl MC, Green P: Base-calling of automated sequencer traces using Phred. I. Accuracy assessment. Genome Res 1998, 8(3): 175-185.

98. Altschul SF, Madden TL, Schaffer AA, Zhang J, Zhang Z, Miller W, Lipman D]: Gapped BLAST and PSI-BLAST: a new generation of protein database search programs. Nucleic Acids Res 1997, 25( I 7):3389-3402

99. Ye J, Fang L, Zheng H, Zhang Y, Chen J, Zhang Z, Wang J, Li S, Li R, Bolund $L$, et al:: WEGO: a web tool for plotting GO annotations. Nucleic Acids Res 2006, 34(Suppl_2):W293-297.

100. Pontius JU, Wagner L, Schuler GD: UniGene: a unified view of the transcriptome. The NCBI Handbook 2003 [http:// www.ncbi.nlm.nih.gov/sites/entrez?db=unigene]. Bethesda (MD): National Center for Biotechnology Information 